\title{
A Wide Stopband Balun Bandpass Filter with Its Application to Balanced Quasi-Yagi Antenna
}

\author{
Gang Zhang ${ }^{(D)}$, Zhenyao Qian, Yushou Chen $\mathbb{D}^{\mathrm{D}}$, and Yang Zhao \\ School of Electrical and Automation Engineering, Nanjing Normal University, Nanjing, China \\ Correspondence should be addressed to Yushou Chen; yushou_chen_nnu@126.com
}

Received 11 December 2017; Accepted 6 March 2018; Published 10 April 2018

Academic Editor: Lei Ge

Copyright (c) 2018 Gang Zhang et al. This is an open access article distributed under the Creative Commons Attribution License, which permits unrestricted use, distribution, and reproduction in any medium, provided the original work is properly cited.

\begin{abstract}
A new microstrip balun bandpass filter (BPF) with wide stopband is presented. It is realized by utilizing the out-of-phase feature of standing-wave distribution on a half-wavelength $(\lambda / 2)$ open-ended microstrip line and the resonant characteristics of the triplemode resonators. For demonstration, a prototype balun BPF operating at central frequency $\left(f_{0}\right)$ of $2.34 \mathrm{GHz}$ with fractional bandwidth (FBW) of about $16.7 \%$ is designed. The presented balun BPF not only exhibits nice balanced response with $0.47 \mathrm{~dB}$ magnitude imbalance and $4.3^{\circ}$ phase difference but also achieves 30 -dB harmonic suppression up to $6.40 \mathrm{GHz}\left(2.7 f_{0}\right)$. Afterward, this presented design is embedded into a balanced quasi-Yagi antenna to obtain high-selective radiation and wide stopband rejection. Experimental results of the implemented antenna indicate less than $-10 \mathrm{~dB}$ reflection coefficient, $4.49-5.38 \mathrm{dBi}$ gain, and 12.71-19.62 dB front-to-back ratio within the operating bandwidth.
\end{abstract}

\section{Introduction}

A balun bandpass filter (BPF) is an important multifunctional integrated component, which provides both balanced conversion of a balun and bandpass frequency selectivity of a BPF simultaneously, since it can reduce the cost and size of the functional block for modern compact wireless communication systems. Therefore, the studies on balun BPFs have been receiving more attention [1-7].

In [1], a multilayer balun BPF with small size and high performance was proposed. But, the involved design structure and procedure of this circuit are complicated. Based on Marchand balun, a dual-band coupled-line balun filter is proposed in [3]. However, two terminals of the coupled lines utilized by the balun have to be terminated to ground by via holes to obtain the desired characteristics. Another type of balun filter is implemented by combining of microstrip lines, slotlines, and coplanar striplines [4]. Although good performance can be achieved, the balun filter still requires via holes connected to the ground and a large size, which cannot accommodate the growth of modern wireless communication system. In addition, a single dual-mode squareloop resonator or patch resonator was introduced to realize a novel dual-mode balun BPF in $[5,6]$, respectively. While the method itself is simple and ingenious, it is restrained in the loop-type dual-mode resonator or patch resonator, thus limiting its application in other types of dual-mode resonator. Moreover, open-type resonator, which is widely used in microwave circuit design, is utilized to realize balun BPFs with good balanced performance and high frequency selectivity [2, 7]. But its limited bandwidth [7] and stopband suppression [2] of the balun BPFs are not satisfactory and need further improvement, while considering its practical application for feeding antenna. Apart from these above listed designs, a balun BPF [8] based on substrate integrated waveguide cavity concept has also been reported. This design is suitable for high frequency application and exhibits very narrow bandwidth.

This paper is aimed to explore a wide stopband balun BPF design with moderate bandwidth and investigate the feasibility of its practical application into antenna feeding network. At first, by selecting proper coupling topologies between the $\lambda / 2$ open-circuited transmission line and triplemode open-stub loaded resonators, a new planar type triplemode balun BPF with moderate band, wide stopband, and high selectivity is presented in this paper. Our research demonstrates that the proposed balun BPF possesses nice balanced responses across the operation passband with about 


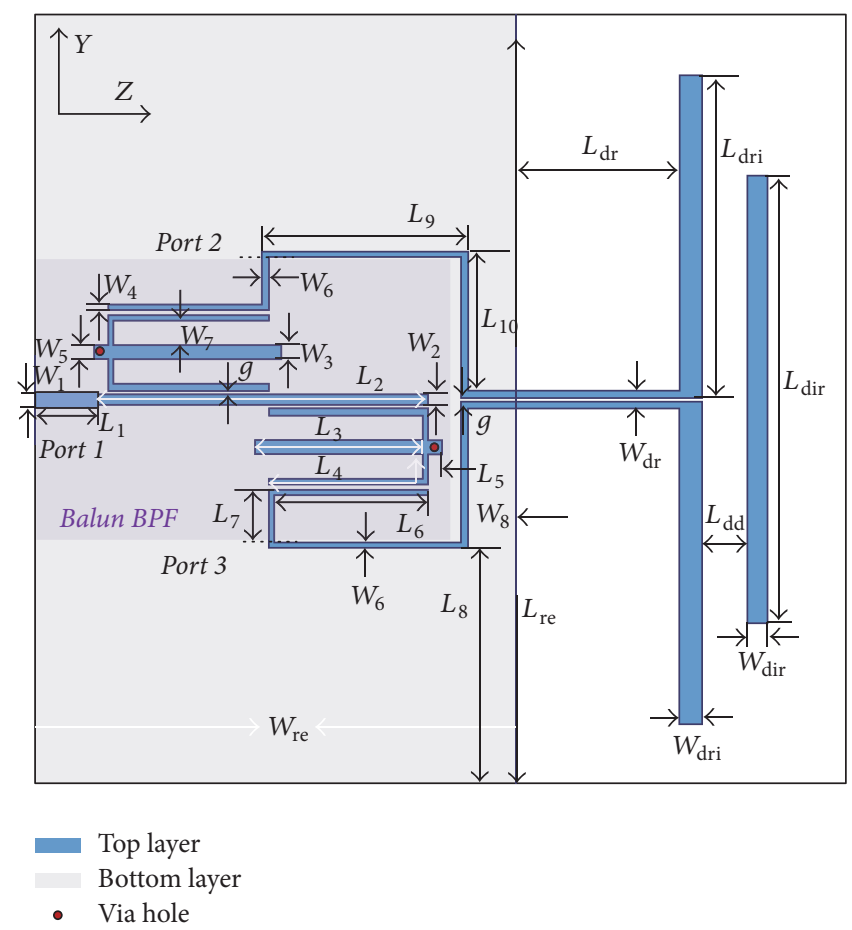

FIgURE 1: Layout of quasi-yagi antenna fed by the proposed balun BPF.

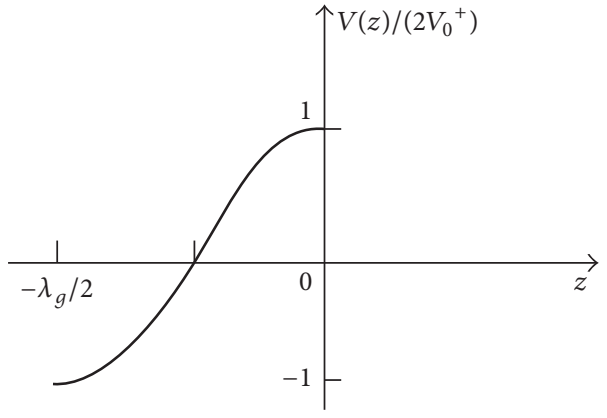

(a)

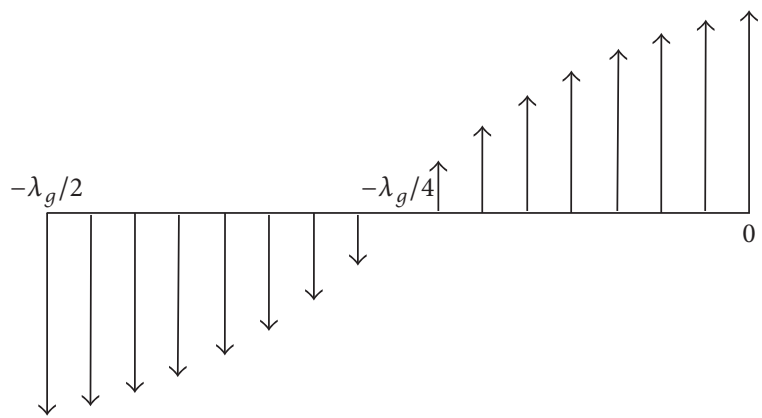

(b)

FIGURE 2: (a) Variation on normalized voltage along a $\lambda / 2$ open-circuited line and (b) its relevant electric field distribution.

$16.7 \% 3-\mathrm{dB}$ fractional bandwidth and $2.7 f_{0}$ harmonic suppression with better than $30 \mathrm{~dB}$ rejection level. Further, the proposed design is embedded into quasi-Yagi antenna as a feeder, for sake of getting high-selective radiation and wide stopband rejection. Both simulated and measured results are displayed to verify these properties predicted in theory.

\section{Proposed Broadband Balun Bandpass Filter}

The configuration of the proposed balun BPF is depicted in the purple shadow section of Figure 1 which mainly consists of a pair of triple-mode resonators and an openended transmission line. Based on the transmission line theory, it can be derived that a standing wave pattern will be yielded when the length of the transmission line is about $\lambda / 2$. The corresponding voltage distribution and electric field distribution are described in Figure 2 [9] in which two distinct regions can be observed with out-of-phase and identical magnitude. These inherent properties can be effectively utilized to meet both the magnitude and the phase requirements of a balun.

Figure 3(a) describes the employed triple-mode resonator in this design, which is symmetrical with respect to its centre plane. Thus, the odd/even-mode method can be applied to analyse its resonance property [10]. The corresponding equivalent circuits are given in Figures 3(b)-3(c). Correspondingly, design equations for the first three resonant frequencies (queued as $f_{1}, f_{2}$, and $f_{3}$ ) and one inherent transmission zero (TZ) frequency $\left(f_{\text {TZ1 }}\right)$ can be derived from input admittances of the odd- and even-mode circuits $\left(Y_{\text {ino }}\right.$ and $\left.Y_{\text {ine }}\right)$, which are given as

$$
Y_{\text {ino }}=-j Y_{4} \cdot \cot \theta_{4}
$$




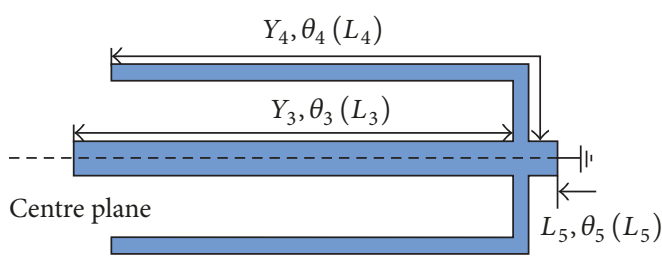

(a)

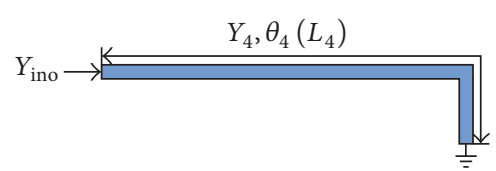

(b)

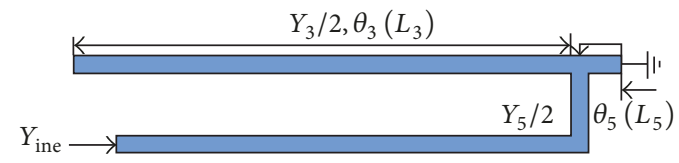

(c)

Figure 3: Triple-mode resonator and its corresponding equivalent circuits, (a) configuration of the proposed triple-mode resonator, (b) odd-mode equivalent circuit, and (c) even-mode equivalent circuit.

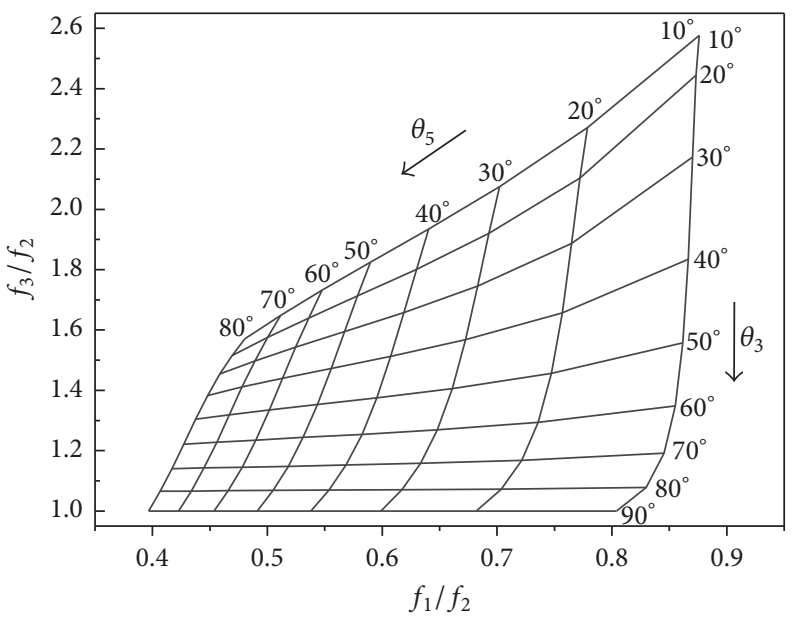

FIGURE 4: Design graph for the triple-mode resonator.

$$
Y_{\text {ine }}=Y_{4} \cdot \frac{K_{e}+j Y_{4} \cdot \tan \theta_{4}}{Y_{4}+j K_{e} \cdot \tan \theta_{4}},
$$

where $K_{e}=\left(-j Y_{5} \cdot \cot \theta_{5}\right) / 2+\left(j Y_{3} \cdot \tan \theta_{3}\right) / 2$.

By setting $Y_{\text {ino }}=0$, the odd-mode resonant frequency can be solved as $\theta_{4}=90^{\circ}$ (for $f_{2}$ ). Meanwhile, when $Y_{\text {ine }}=0$, the even-mode resonant conditions can be simplified as $Y_{5}$. $\cot \theta_{5}-Y_{3} \cdot \tan \theta_{3}=2 Y_{4} \tan \theta_{4}$ (for $f_{1}, f_{3}$ ). In addition, by solving $Y_{\text {ino }}=Y_{\text {ine }}$, one inherent TZ frequency $f_{\mathrm{TZ} 1}$ can be calculated as $\theta_{3}=90^{\circ}$.

Based on the above analysis, a triple-mode resonator can be realized and designed. Specifically, we can figure out from (1) that $f_{2}$ is only determined by $\theta_{4}$, while $f_{1} / f_{2}$ and $f_{3} / f_{2}$ are mainly influenced by $\theta_{5}$ and $\theta_{3}$, respectively. Figure 4 shows the design graph of the tri-mode resonators with a admittance ratio $K=Y_{5} / Y_{3}=1.6$. It can be seen that the smaller $\theta_{5}$ is, the larger $f_{3} / f_{2}$ will be, while the smaller $\theta_{3}$ is, the larger $f_{1} / f_{2}$ will be. The admittance ratio $K$ is added in the design to increase the degree of freedom in determining resonant frequencies $f_{1}$ and $f_{3}$ allocation. Thus, one can decide $f_{1}$ and $f_{3}$ by properly adjusting $\theta_{5}, \theta_{3}$, and $K$, while remaining $f_{2}$ unchanged. On the other hand, $Y_{\text {ino }}=Y_{\text {ine }}$ indicates that the inherent $f_{\mathrm{TZ1}}$ could be controlled by $\theta_{3}$. Therefore, these demonstrated properties are very useful for one to realize a balun BPF with filtering performance of desired bandwidth and high selectivity.

Based on the aforementioned illustration, a balun BPF is constructed as depicted in Figure 1. As it presents, two identical stubs-loaded resonators are placed symmetrically in the two above regions in Figure 2 featured with equal magnitude and contrary phase. Due to this arrangement, the couplings between the transmission line and two resonators can be characterized with the same amplitude and out of phase. Thus, a pair of balanced signals between ports 2 and 3 is finally achieved. Additionally, the input/output coupled structures are introduced by properly orienting the resonators to realize good filtering behaviour. Since the desired absolute bandwidth of triple-mode Balun BPF is approximate to $f_{3}-f_{1}$ and the centre frequency can be deemed as $f_{2}$, initial dimensions of the resonators and openended transmission line can be obtained. Besides, dimensions of the input/output $(\mathrm{I} / \mathrm{O})$ coupling line structure can be determined by fine tuning the parameters, that is, width $\left(W_{2}\right)$ and gap $(g)$ of the I/O coupled-lines so as to satisfy the given bandwidth. 
TABLE 1: Dimensions of the proposed Balun BPF.

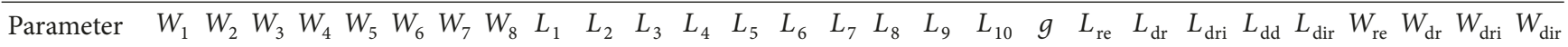

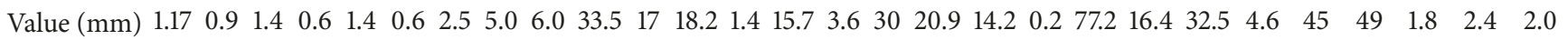

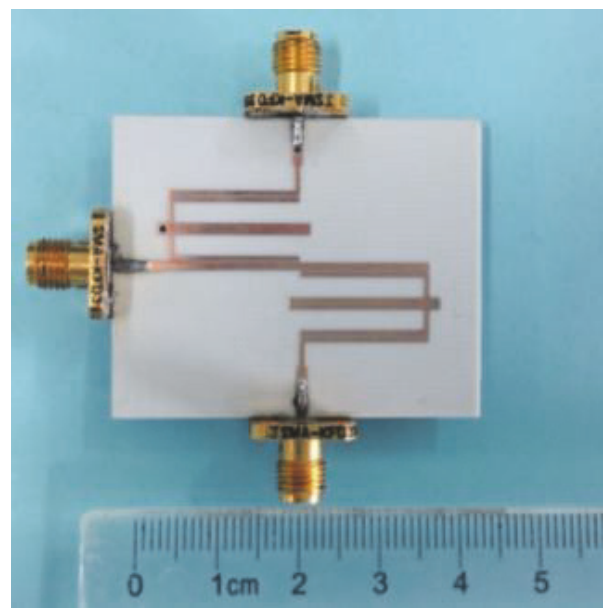

FIGURE 5: Photograph of the fabricated balun BPF.

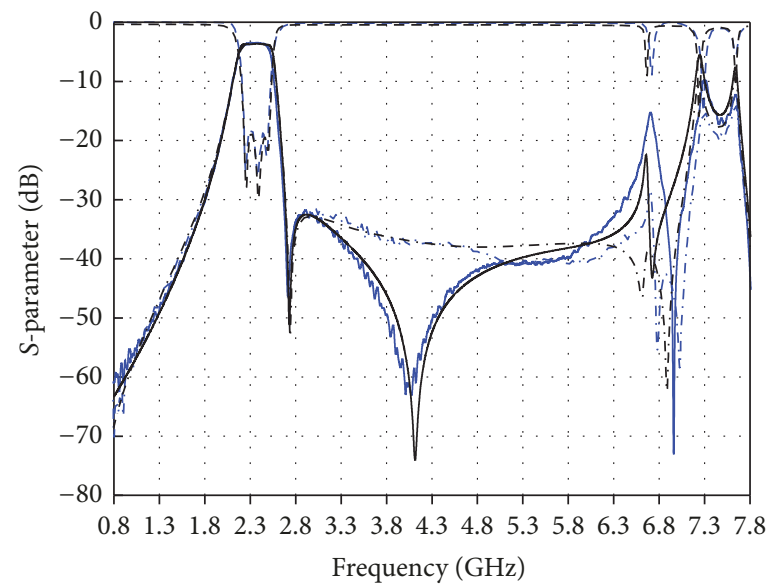

$\begin{array}{ll}- \text { Measured- } S_{21} & - \text { Simulated }-S_{21} \\ --- \text { Measured }-S_{31} & --\cdot \text { Simulated }-S_{31} \\ --- \text { Measured- } S_{11} & --- \text { Simulated }-S_{11}\end{array}$

(a)

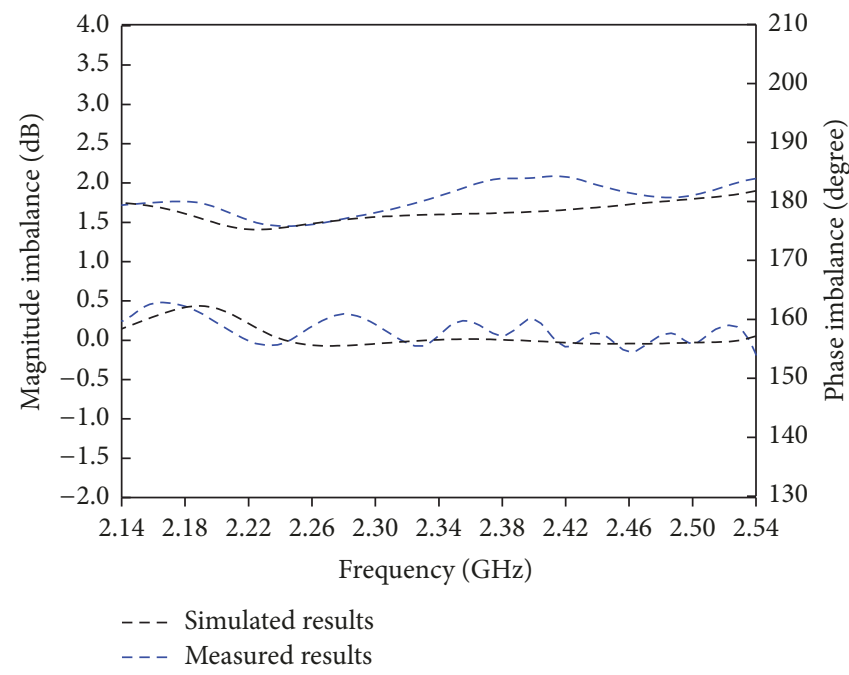

(b)

FIGURE 6: Simulated and measured results of the proposed balun BPF, (a) S-parameters of the balun BPF, and (b) magnitude imbalance and phase imbalance of the presented balun BPF.

For validation, a prototype centered at $2.34 \mathrm{GHz}$ is designed in this work. It is implemented on the substrate of Rogers RO4003C with a dielectric constant $\varepsilon_{r}=3.55$, a loss tangent $\tan \delta=0.0027$, and a thickness $h=0.508 \mathrm{~mm}$. The optimal physical dimensions of the design are denoted as Table 1 with the diameter $(D=0.4 \mathrm{~mm})$ of the metallic via hole. The balun BPF was simulated by commercial software ANSYS EM 16.1, and the corresponding fabricated circuit shown in the inset plot of Figure 5 was measured with the Agilent N5244A four-port vector network analyzer. Simulated and measured results depicted in Figure 6 show a good agreement with each other. Measured results indicate that the proposed balun BPF operates at the central frequency of
$2.34 \mathrm{GHz}$ with a $3-\mathrm{dB}$ fractional bandwidth of $17.6 \%$. Within the passband, the balun filter exhibits with a minimum insertion loss of $0.7 \mathrm{~dB}$ and maximum return loss of $17.8 \mathrm{~dB}$. Outside the passband, one common TZ located at $2.71 \mathrm{GHz}$ is observed for both $S_{21}$ and $S_{31}$. Besides, an additional TZ located at $4.01 \mathrm{GHz}$ for $S_{21}$ can be seen, which might be caused by the resonance of the input transmission line. These TZs ensure high out-of-band selectivity of the Balun BPF. What is more, the balun BPF also exhibits $30-\mathrm{dB}$ harmonic suppression up to $6.40 \mathrm{GHz}\left(2.7 f_{0}\right)$. For the performance between two output ports, the maximum in-band magnitude imbalance is about $0.47 \mathrm{~dB}$ and the phase difference is within $4.3^{\circ}$. The small discrepancies between measured results and 


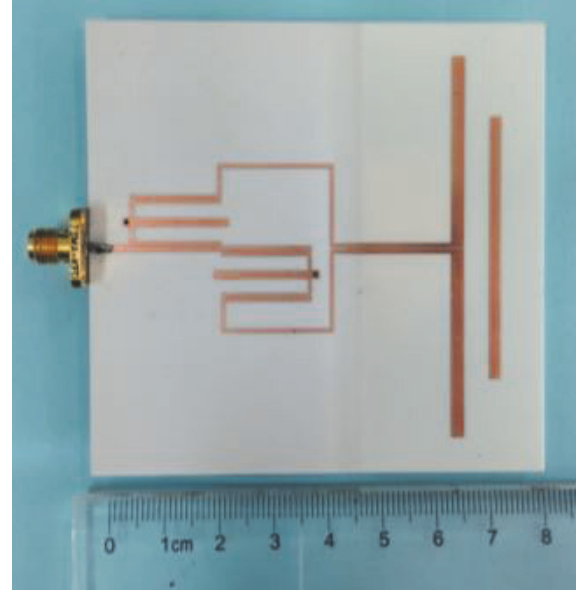

(a)

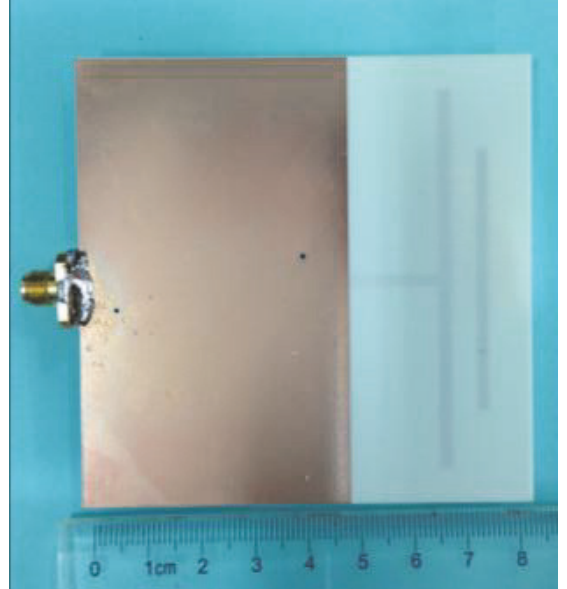

(b)

FIgURE 7: Photograph of the fabricated antenna, (a) top view, and (b) bottom view.

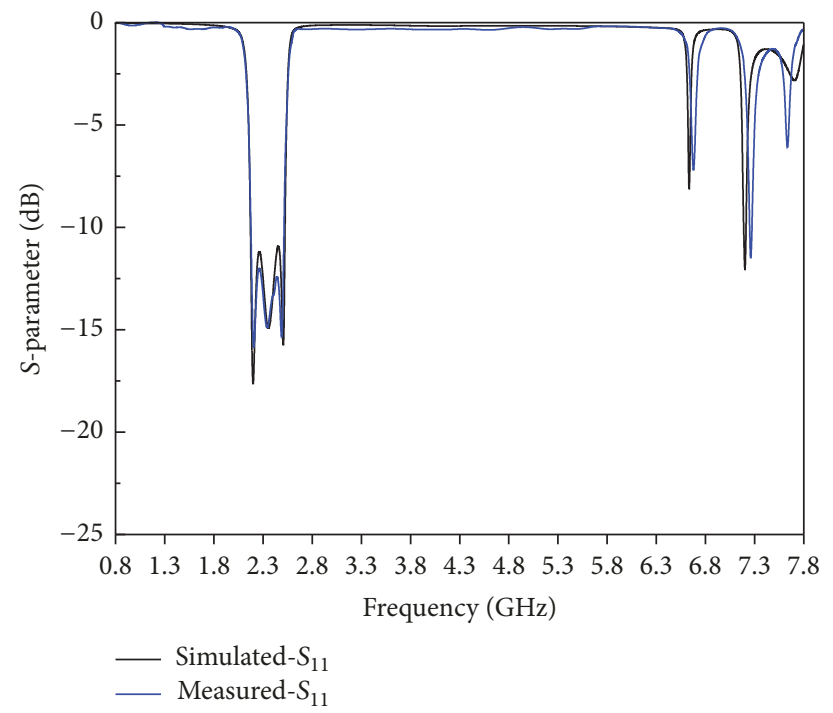

Figure 8: Simulated and measured reflection coefficient of the quasi-Yagi antenna.

simulated results are mainly attributed to the fabrication error and minor SMA connection difference between port 2 and port 3. Table 2 tabulates the performances in comparison with the proposed BPF and other reported ones. It can be seen that our work exhibits wider operation bandwidth, low phase imbalance, and good harmonic suppression against others.

\section{Balun BPF Feeding Broadband Quasi-Yagi Antenna}

Aiming to achieve good radiation performance, wide stopband rejection, and high selective radiation, the proposed balun BPF is further employed to feed a moderate-band balanced quasi-Yagi antenna as shown in Figure 1. The quasiYagi is designed with two rectangle-shaped radiation arms as the dipole driver and one rectangle-shaped patch as the director [11]. One sectional folded microstrip line is utilized herein for the integration of the balun and antenna and the input impedance matching. Besides, to achieve desired bandwidth, the spacing $L_{\mathrm{dd}}$ between the parasitic director and dipole driver is chosen less than a quarter-wavelength. As for the spacing $L_{\mathrm{dr}}$ between the dipole driver and truncated ground plane, it should be chosen as about a quarter-wavelength so as to create an in-phase reflected wave along the endfire direction. The detailed geometric parameters are listed in Table 1 . The designed antenna fed by balun BPF is then fabricated and tested. Figure 7 shows its top- and bottomview photographs. The reflection coefficient is measured by the N5244A Network Analyzer, while the radiation patterns, gains, and efficiency of this antenna were measured by employing the Microwave Vision Group's Starlab near-field antenna measurement system. Measured reflection coefficient plotted in Figure 8 indicates that the operating band of the antenna ranges from $2.17 \mathrm{GHz}$ to $2.52 \mathrm{GHz}$ (FBW of about $15 \%$ ) with smaller than $-10 \mathrm{~dB}$ reflection coefficient. It can be found that the implemented quasi-Yagi antenna possesses a well-defined return-loss curve without undesired radiation up to $2.75 f_{0}$ outside the passband. Figures 9 (a)-9(f) 


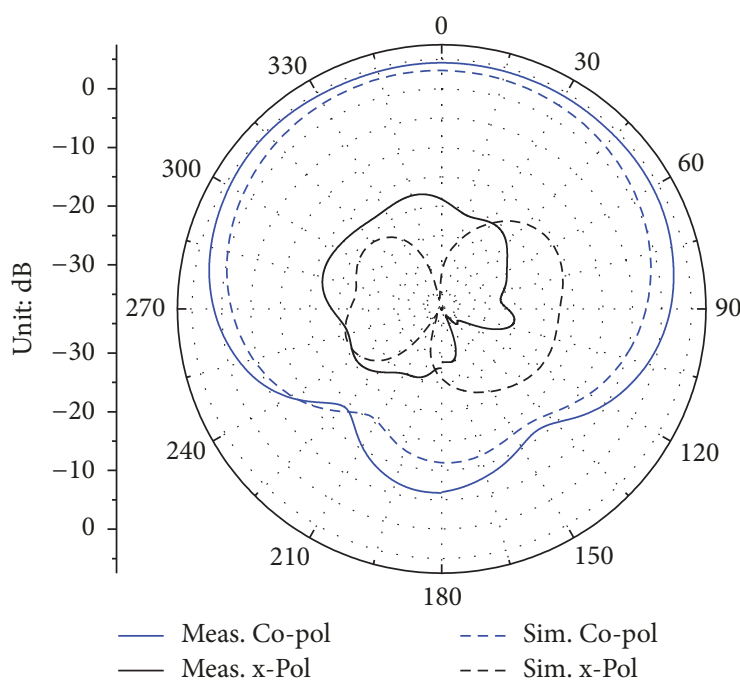

(a)

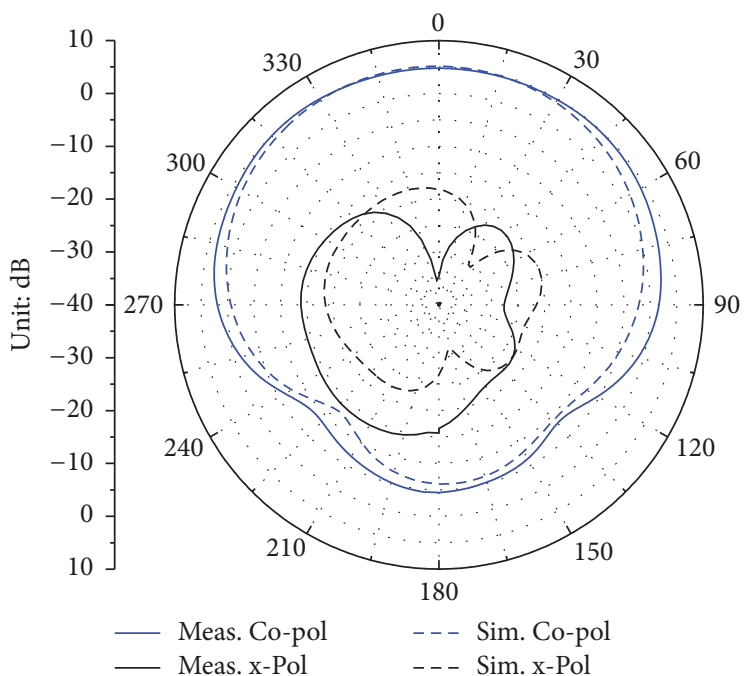

(c)

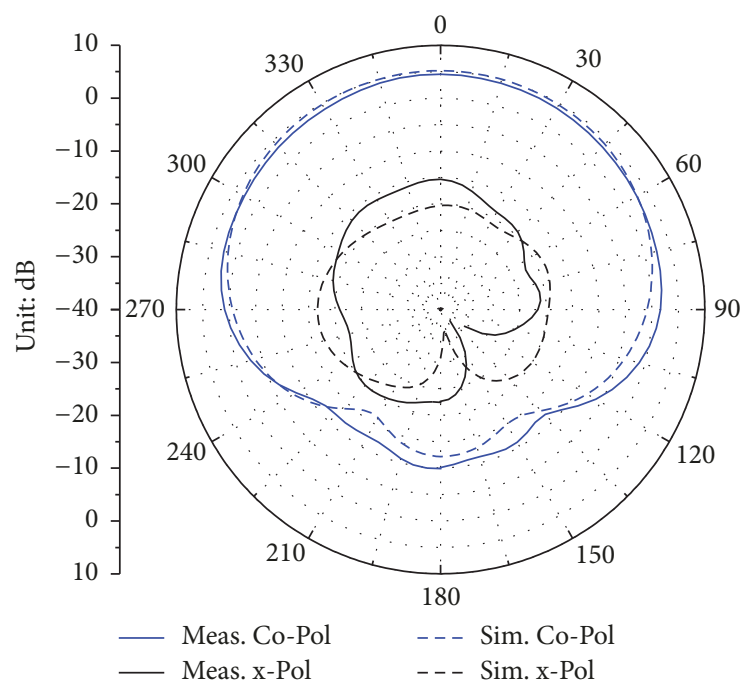

(e)

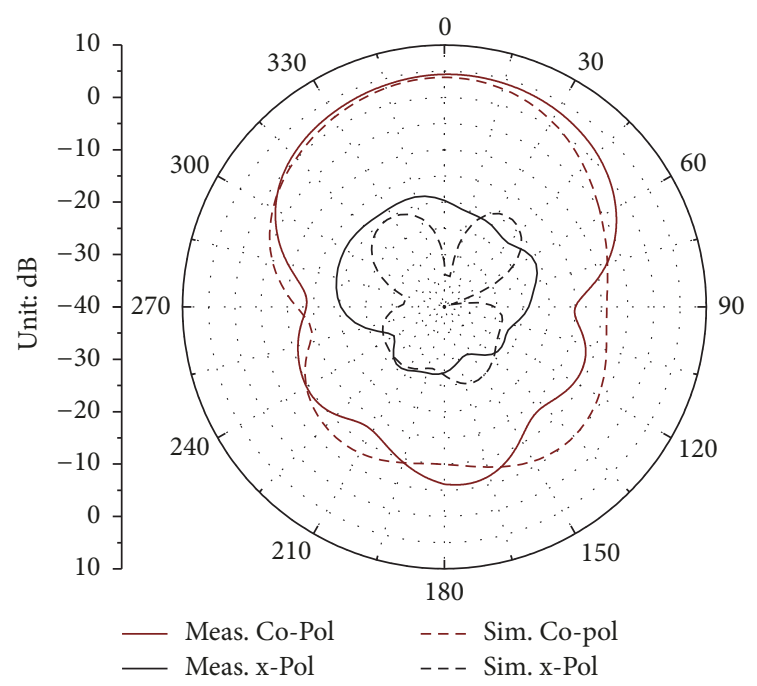

(b)

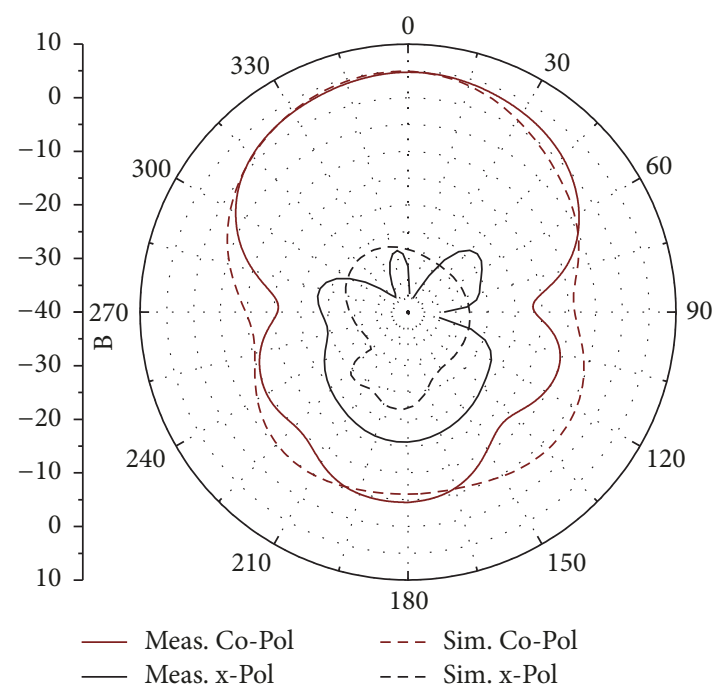

(d)

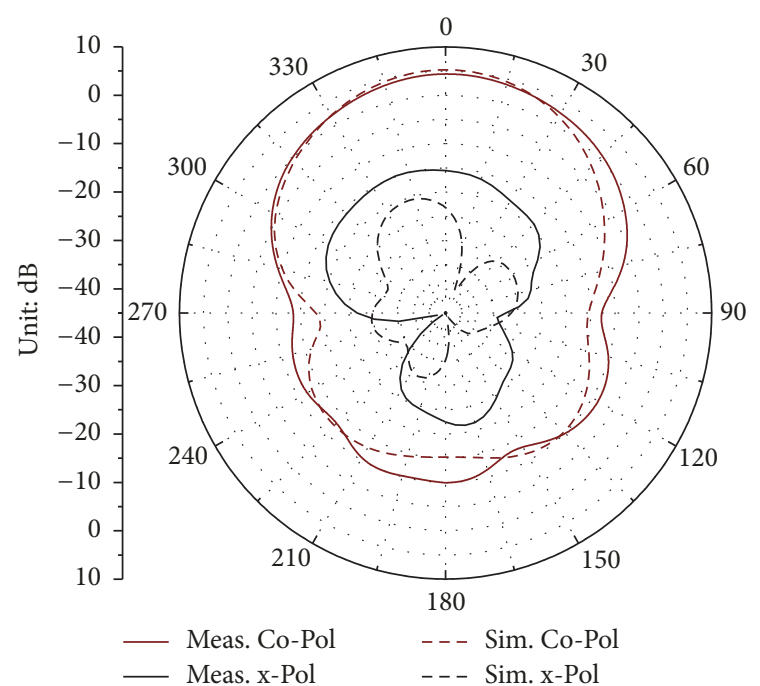

(f)

FIGURE 9: Simulated and measured radiation patterns at two frequencies, (a) $x z$-plane at $2.34 \mathrm{GHz}$, (b) $y z$-plane at $2.34 \mathrm{GHz}$, (c) $x z$-plane at $2.2 \mathrm{GHz}$, (d) $y z$-plane at $2.2 \mathrm{GHz}$, (e) $x z$-plane at $2.5 \mathrm{GHz}$, and (f) $y z$-plane at $2.5 \mathrm{GHz}$. 
TABLE 2: Comparisons among proposed and other reported Balun BPFs.

\begin{tabular}{lccccc}
\hline Ref. & $f_{0}(\mathrm{GHz})$ & 3 -dB FBW & Amplitude imbalance & Phase imbalance & 30-dB harmonic suppression \\
\hline$[5]$ & 2.55 & $3.5 \%$ & $<1.10 \mathrm{~dB}$ & $<5^{\circ}$ & $1.5 f_{0}$ \\
{$[6]$} & 3.48 & $5.8 \%$ & $<0.50 \mathrm{~dB}$ & $<5^{\circ}$ & None \\
{$[7]$} & 2.00 & $11.0 \%$ & $<0.35 \mathrm{~dB}$ & $<5^{\circ}$ & None \\
This work & 2.34 & $16.7 \%$ & $<0.47 \mathrm{~dB}$ & $<4.3^{\circ}$ & $2.7 f_{0}$ \\
\hline
\end{tabular}

Ref.: references, $f_{0}$ : centre frequency, and FBW: fractional bandwidth.

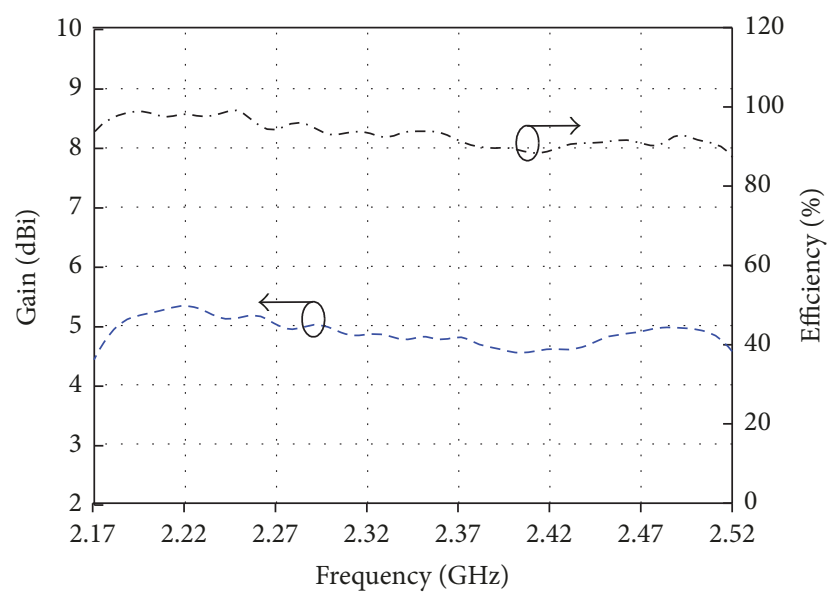

FIGURE 10: Measured gain and efficiency of the integrated quasi-Yagi antenna.

indicate the measured radiation patterns on $Y Z$-plane $(E$ plane) and $X Z$-plane ( $H$-plane). The results depicted in Figure 9 confirm the directive properties of the antenna. The front-to-back ratio of the antenna varies from $10.6 \mathrm{~dB}$ at $2.35 \mathrm{GHz}$ to $14.4 \mathrm{~dB}$ at $2.5 \mathrm{GHz}$. In addition, Figure 10 illustrates the measured gain and efficiency. The realized gain is approximately $4.49-5.38 \mathrm{dBi}$ and the efficiency is more than $88.6 \%$ across the band from $2.17 \mathrm{GHz}$ to $2.52 \mathrm{GHz}$.

\section{Conclusion}

In this paper, a new design of wide stopband balun BPF has been proposed. Owing to the standing-wave distribution on a half-wavelength open-ended microstrip line, signals with equal magnitude and contrary phase are simultaneously obtained at two output ports. Furthermore, by using the even-/odd-mode analysis method, the filtering responses have been figured out with the bisected equivalent circuit of the employed resonator. To further explore it in the practical antenna application, a quasi-Yagi antenna fed by the proposed balun BPF is designed for high selective radiation and wide stopband rejection. Both simulated and measured results verify the feasibility of the presented designs.

\section{Conflicts of Interest}

The authors declare that there are no conflicts of interest regarding the publication of this paper.

\section{References}

[1] X. F. Liu, X. Y. Zhang, and K.-X. Wang, "Compact LTCC balun filter using folded half-wavelength resonators," in Proceedings of the IEEE International Wireless Symposium, IWS 2015, China, April 2015.

[2] G. Zhang, J. Wang, and W. Wu, "Wideband balun bandpass filter explored for a balanced dipole antenna with high selectivity," IEEE Electronics Letters, vol. 52, no. 13, pp. 1153-1155, 2016.

[3] L. K. Yeung and K. L. Wu, "A dual-band coupled-line balun filter," IEEE Transactions on Microwave Theory and Techniques, vol. 55, no. 11, pp. 2406-2411, 2007.

[4] Y.-W. Lin, J.-C. Lu, and C.-Y. Chang, "Design of high-order wideband planar balun filter in S-plane bandpass prototype," IEEE Transactions on Microwave Theory and Techniques, vol. 60, no. 7, pp. 2124-2130, 2012.

[5] P. Cheong, T.-S. Lv, W.-W. Choi, and K.-W. Tam, "A compact microstrip square-loop dual-mode balun-bandpass filter with simultaneous spurious response suppression and differential performance improvement," IEEE Microwave and Wireless Components Letters, vol. 21, no. 2, pp. 77-79, 2011.

[6] X. F. Ye, Y. Z. Shi, E. Guo, and S. Y. Zheng, "A bandpass filtering balun based on circular sector patch," in Proceedings of the 5th IEEE Asia-Pacific Conference on Antennas and Propagation, APCAP 2016, pp. 21-22, Taiwan, July 2016.

[7] F. Huang, J. Wang, and L. Zhu, "A New Approach to Design a Microstrip Dual-Mode Balun Bandpass Filter," IEEE Microwave and Wireless Components Letters, vol. 26, no. 4, pp. 252-254, 2016.

[8] H. Gu, J. Wang, G. Zhang, and J.-L. Li, "Design of a SIW balun bandpass filter with high selectivity," Journal of Electromagnetic Waves and Applications, vol. 30, no. 1, pp. 61-69, 2016.

[9] D. M. Pozar, Microwave Engineering, John Wiley Sons Press, New York, 3rd edition, 2005.

[10] J. Hong and M. J. Lancaster, Microstrip Filters for RF/Microwave Applications, John Wiley \& Sons, New York, NY, USA, 2001.

[11] Y. Qian, W. R. Deal, N. Kaneda, and T. Itoh, "Microstripfed quasi-Yagi antenna with broadband characteristics," IEEE Electronics Letters, vol. 34, no. 23, pp. 2194-2196, 1998. 


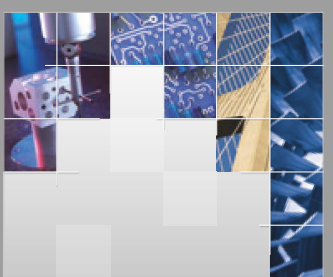

\section{Enfincering}
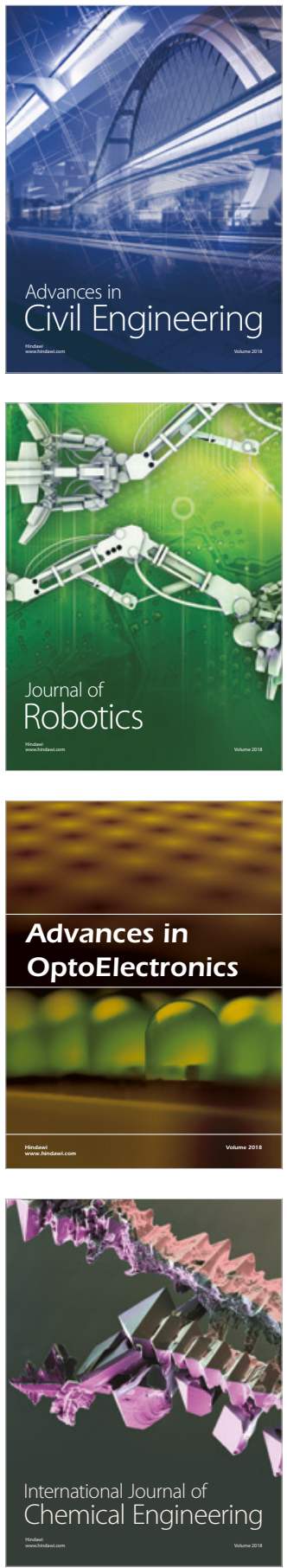

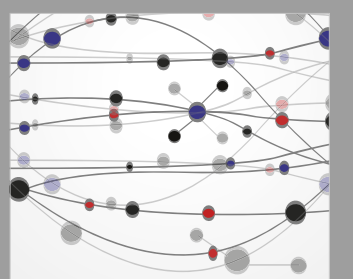

\section{Rotating \\ Machinery}

The Scientific World Journal

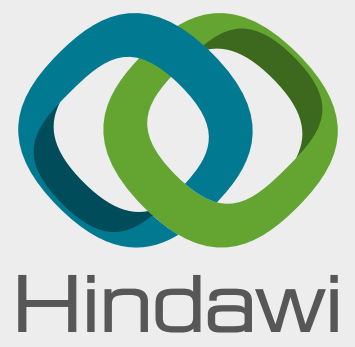

Submit your manuscripts at

www.hindawi.com
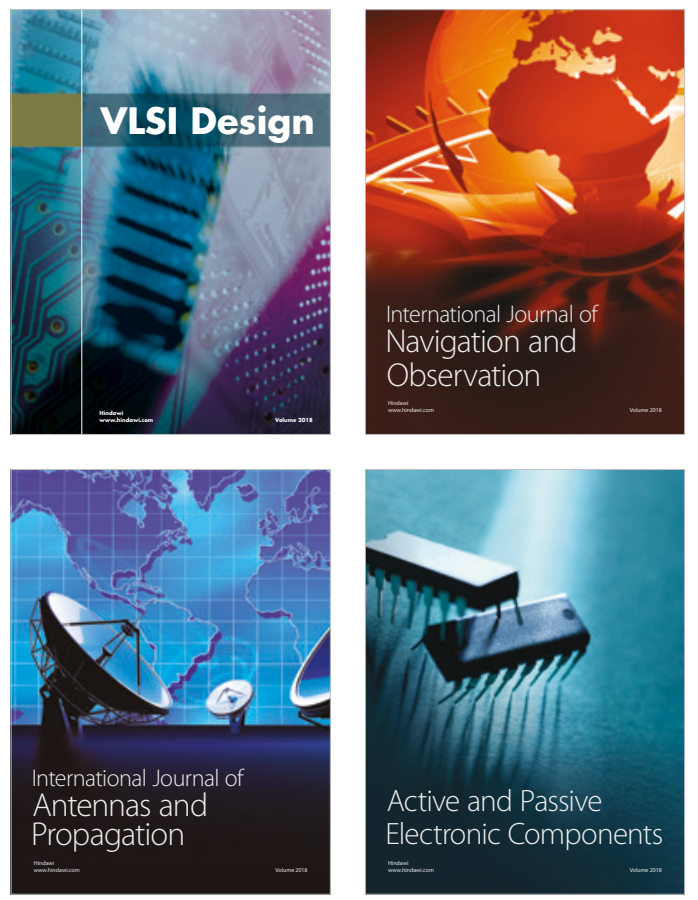
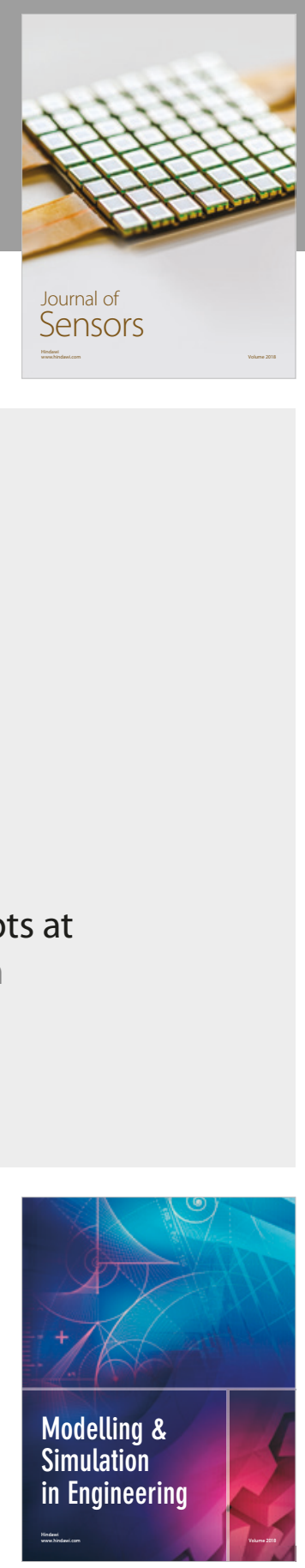

\section{Advances \\ Multimedia}
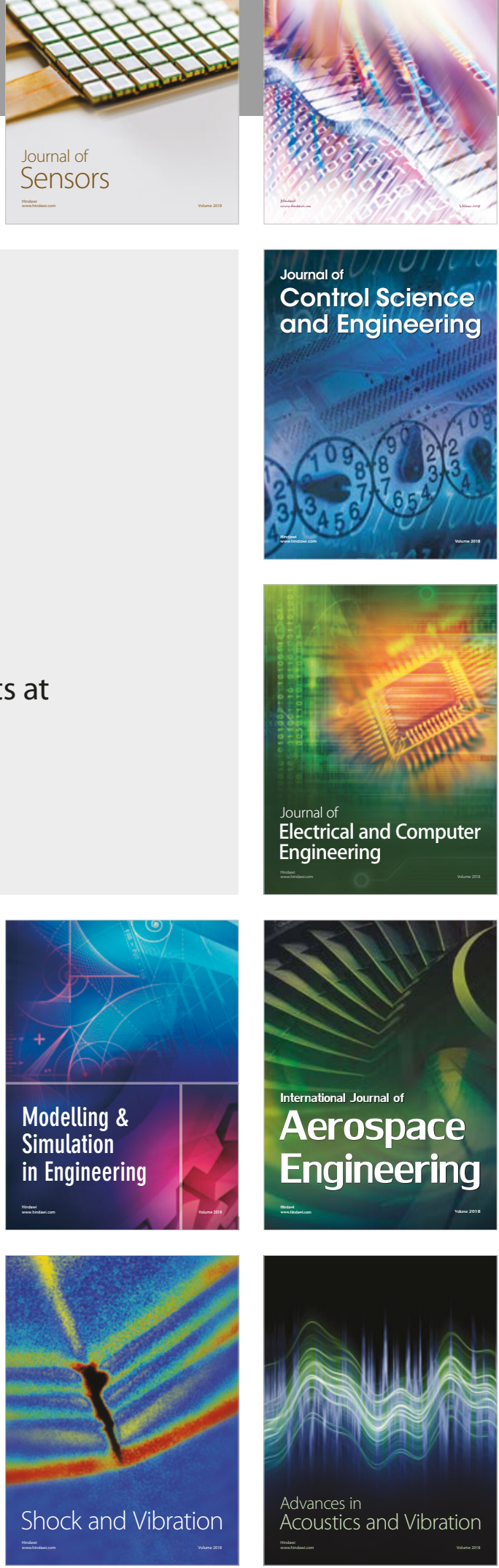